\title{
Endocrinology, energetics, and human life history: A synthetic model
}

\section{Citation}

Ellison, Peter T. 2017. “Endocrinology, Energetics, and Human Life History: A Synthetic Model.” Hormones and Behavior 91 (May): 97-106. doi:10.1016/j.yhbeh.2016.09.006.

\section{Published Version}

doi:10.1016/j.yhbeh.2016.09.006

\section{Permanent link}

http://nrs.harvard.edu/urn-3:HUL.InstRepos:34221115

\section{Terms of Use}

This article was downloaded from Harvard University's DASH repository, and is made available under the terms and conditions applicable to Open Access Policy Articles, as set forth at http:// nrs.harvard.edu/urn-3:HUL.InstRepos:dash.current.terms-of-use\#OAP

\section{Share Your Story}

The Harvard community has made this article openly available.

Please share how this access benefits you. Submit a story.

Accessibility 
1 Endocrinology, Energetics, and Human Life History: A Synthetic Model

3 Peter $\mathrm{T}$. Ellison

4 Department of Human Evolutionary Biology

5 Harvard University

6

9 Abstract

Human life histories are shaped by the allocation of metabolic energy to

13 competing physiological domains. A model framework of the pathways of energy

14 allocation is described and hormonal regulators of allocation along the pathways of the

15 framework are discussed in the light of evidence from field studies of the endocrinology

16 of human energetics. The framework is then used to generate simple models of two

17 important life history transitions in humans, puberty and the postpartum return to full

18 fecundity in females. The results of the models correspond very closely to observations

19 made in the field. 


\section{Introduction}

25 The essence of life can be defined as "metabolism in the service of

26 reproduction." Organisms capture energy from the environment and turn it into more

27 organisms. Natural selection has favored those variations that perform this task more

28 reliably and more efficiently than their competitors. But the route from energy capture to

29 reproduction can be complex. Even in the simplest organisms some captured energy

30 must be devoted to growth and maintenance of the organism as well as to reproduction.

31 Reproduction without growth would rapidly lead to smaller and smaller organisms until

32 the size limits of viability were reached. Investment in maintenance leads to increased

33 survivorship and opportunities to continue reproducing. The partitioning of available

34 energy among these non-overlapping categories gives rise to the patterning of life

35 histories -- variation in age-specific probabilities of mortality and fertility, trajectories of

36 growth, rates of senescence, and other aspects of phenotype that are only manifest in a

37 diachronic view, in the way an organism's life unfolds rather than in its state at any

38 given time.

Life history theory emphasizes trade-offs and how optimal energy allocation

41 varies with age and environmental circumstances. But this body of theory often leaves

42 unspecified the physiological mechanisms that govern and regulate those trade-offs.

43 The field of human reproductive ecology has emerged out of an effort to understand

44 those mechanisms as they relate to the regulation of reproductive effort in particular 
45 (Ellison, 2003a, 2009). More recent efforts to illuminate the mechanisms governing

46 trade-offs of investment in growth and immune function are helping to further advance

47 an integration of the physiological mechanisms of energy allocation decisions with the

48 conceptual framework of life history theory (Flatt and Heyland, 2011). The focus of this

49 paper will be a consideration of the ways the endocrine system helps to regulate

50 metabolic energy allocation to generate the structure of human life history.

The endocrine system is one of the three major systems of integration of

53 vertebrate physiology based on molecular communication, the other two being the

54 nervous system and the immune system. The power of the endocrine system as a

55 physiological integrator lies in two properties: (i) the diffuse nature of its communication,

56 reaching all cells of the organism, and (ii) its ability to regulate both cellular activity and

57 gene expression. Together these properties position the endocrine system to regulate

58 energy allocation in ways that integrate with developmental and life history changes.

There are, however, two frequent biases in endocrinology that we should be

61 particularly aware of in considering the regulation of metabolic energy allocation: the

62 "top down bias" and the "newcomer bias." The top down bias is manifest in a

63 predilection for assuming that the brain is in charge of the body. In many areas this is

64 true, but it is not an absolute hierarchy of regulation. Elsewhere (Ellison, 2009) I have

65 noted that molecular communication can be classified by the channels through which it

66 flows into (a) central-nervous-system (CNS)-to-soma, (b) soma-to-CNS, (c) soma-to- 
67 soma, and, (d) CNS-to-CNS. Behavioral endocrinology is dominated by soma-to-CNS

68 communication, coordinating behavior with the physiological state of the organism,

69 particularly as regards the regulation of reproductive effort. The most potent

70 messengers along this pathway are those that easily cross the blood-brain barrier,

71 especially steroids, as well as peptides that gain access to the basal hypothalamus.

72 CNS-to-soma communication primarily flows through the hypothalamic-pituitary

73 "transducer", integrating sensory and other information from basal ganglia and higher

74 cortical areas in the regulation of peripheral organs and endocrine glands. Larger

75 protein molecules are typical messengers along this pathway. Both the soma-to-CNS

76 and CNS-to-soma channels can have important effects on the allocation of metabolic

77 energy. But the primary conduit for messages regulating energy allocation is the soma-

78 to-soma channel. This pathway includes messengers of all chemical types, including

79 steroids (both gonadal and adrenal), thyroid hormones, proteins (including pancreatic

80 hormones), and peptides (including gut hormones and adipokines). In large part, as will

81 be described, the action of messages flowing through the CNS-to-soma pathway on

82 energy allocation is achieved by modifying the action of messages in the soma-to-soma

83 pathway.

85 The newcomer bias is manifested in a natural fascination with newly discovered

86 or described messenger molecules and the desire to see them as particularly important

87 in their effects. This can often be the case, but should not cause us to neglect the

88 central roles that are often played by those messengers who have long featured in our 
89 understanding of endocrine physiology. Many of these, such as steroids, thyroid

90 hormones, pancreatic and gut hormones, also feature prominently in the soma-to-soma

91 channel.

92

93 Keeping these biases in mind, we can consider the major features of the

94 endocrine regulation of energy allocation decisions and their impact on human life

95 history. The framework described here will necessarily be an over-simplification, like all

96 models. Yet hopefully it will capture enough of the important features of the system to

97 be heuristic, in organizing and synthesizing information, in illuminating complex

98 interactions and processes, and in generating hypotheses. Where possible, we will pay

99 attention to evidence from and applications to field studies of human physiology.

100

101 The endocrine framework of human energetics

102

103 The basic framework of human energetics, the flow of energy through the

104 organism, is represented by the diagram in Figure 1 where the pathways indicated by

105 specific arrows are associated with the hormonal regulators shown in Figure 2. As a

106 model, not all the pathways of physiological integration and regulation that affect

107 energetics are included, nor all the potential endocrine signals involved. Those that are

108 included are considered to be major pathways and regulators which account for major

109 aspects of energy allocation and its life history effects. 
At the center of the framework is "available metabolic energy," available for

112 immediate allocation to any one of a number of non-overlapping categories. Inputs to

113 available metabolic energy come either from direct intake, or from stores, filtered by the

114 regulation of ATP production. The major allocation categories for available metabolic

115 energy are identified as storage, activity, anabolism, and maintenance. Anabolic sub-

116 categories include growth and reproduction. The parts of this framework will be

117 considered in turn.

$\underline{\text { Regulation of energy balance }}$

Energy balance refers to the difference between energy intake through nutrition

123 and energy expenditure through all metabolic pathways. Of the various pathways of

124 energy expenditure, physical activity can be separated out as distinct from those that

125 contribute to resting metabolic rate. The net of energy intake and expenditure in activity

126 can be considered as the contribution to available metabolic energy from the

127 environment.

129 Energy intake is not tightly regulated by the endocrine system, since it depends

130 greatly on environmental factors. Appetite regulation, however, is strongly affected by

131 endocrine signals (Badman and Flier, 2005; Blundell et al., 2015a; Blundell et al.,

132 2015b; Crespo et al., 2014; Meier and Gressner, 2004; Schwartz, 2000; Schwartz et al., 
133 2000; Webber et al., 2015). Two signaling molecules that will be considered in this

134 model are leptin and ghrelin. Both are peptides, principally produced in the soma but

135 capable of some penetration of the blood-brain barrier. Leptin is primarily produced by

136 adipocytes, ghrelin by the gut. Both carry information to the hypothalamus that can

137 affect appetite. Leptin, a tonic hormone reflecting the mass of adipocytes, is associated

138 with reduced hunger when circulating levels are high and increased hunger when levels

139 are low (Schwartz et al., 2000). Ghrelin, an episodic hormone which reflects short-term

140 status of gut contents, with high levels occurring when the gut is relatively empty for an

141 extended period, stimulates hunger when its levels are high (Pinkney, 2014). These

142 orexigenic effects are mediated by and coordinated with other neural signaling, primarily

143 in the ventromedial hypothalamus (Webber et al., 2015).

Energy expenditure in activity is not under tight hormonal control in humans, but

146 in rodent models, lowered leptin levels were early observed to correlate with increased

147 levels of physical activity, perhaps reflecting a stimulation of the motivation to forage for

148 food (Pelleymounter et al., 1995; Wolf, 1996). In many rodents, food foraging exposes

149 the animal to significant predation risk. Appetite regulation may serve to help regulate

150 foraging effort in a way that balances risks versus benefits. There is no evidence at this

151 time that foraging effort in human hunter-gatherer societies (the evolutionarily salient

152 human subsistence pattern) or any other ecological context is related to hormonal

153 appetite regulation. However, there is clinical evidence that exercise may affect

154 appetite through the mediation of appetite regulating hormones (Blundell et al., 2015b). 
156 Studies of human leptin and ghrelin levels in the field have produced some

157 notable results, particularly highlighting population variation in average levels

158 (Bribiescas, 2001, 2005; Bribiescas and Hickey, 2006; Kuzawa et al., 2007; Miller et al., 159 2006; Munch-Andersen et al., 2013; Sharrock et al., 2008; Tanaka et al., 2005). In

160 general, subjects in non-western populations and populations engaged in subsistence

161 economies have significantly lower levels of both appetite regulating hormones than in

162 western, developed societies. This is true for leptin even after correcting for fat mass.

163 At the least this suggests that caution needs to be exercised in interpreting the 164 significance of absolute levels of these hormones. It is likely that the set-points for

165 appetite regulation may be influenced by developmental factors (Sharrock et al., 2008)

166 and may reflect population differences in overall energy budgets.

169 Regulation of energy availability

173 Oxidizable substrates (principally carbohydrates and fatty acids) are released

174 from stores into the blood stream under the regulation of several different hormones.

175 Among the most important regulators of energy substrate release in humans are

176 cortisol, epinephrine, and glucagon. Epinephrine and glucagon are relatively short-term 
177 regulators, involved in defending blood sugar homeostasis against the vagaries of

178 intake and expenditure on a time scale of minutes to hours. Because of their short-term

179 effects, these hormones are often involved in behavioral responses, including "fight or

180 flight" scenarios. However, they are not directly implicated in the longer term regulation

181 of energy substrate release that is typically involved in life history strategies and

182 transitions.

185 substrate availability. Cortisol has been associated with responses to psychosocial

186 stress, to the extent that it is frequently referred to as a "stress" hormone. However, it

187 can be misleading to label cortisol in this way, since psychosocial stress is only one

188 potential trigger for its release. Other than categorizing cortisol by one of the multiple

189 factors the can cause its release, it would be better to categorize it by its downstream

190 effects as a "metabolic" hormone. Cortisol's principal actions involve the stimulation of

191 lipolysis to release fatty acids from adipose stores and the antagonism of

192 gluconeogenesis, resulting in an increase in available oxidizable substrates (Widmaier

193 et al., 2013). Although cortisol is elevated as a consequence of short-term stresses, it

194 rapidly returns to baseline when those stresses are removed. Chronic energy

195 demands, as can occur with infection and undernutrition (or, in other animals, migration

196 and hibernation), can result in chronically elevated cortisol and a shift toward greater

197 reliance on stored energy reserves. Shifts in chronic cortisol release also occur with 
198 reproductive state in human females, being elevated during pregnancy to mobilize

199 maternal fat reserves to support fetal growth (Widmaier et al., 2013).

201 It should be noted that while cortisol promotes the release of free fatty acids via 202 lipolysis, it does not stimulate the beta oxidation pathway by which fatty acids gain entry

203 to the tricarboxylic acid cycle (Widmaier et al., 2013) Pathological elevation of cortisol

204 without increased energy expenditure, as in Cushing's syndrome, can result in

205 excessive fat accumulation in adipose depots and ectopic locations less sensitive to

206 cortisol action and thus be associated with redistribution of fat rather than loss of fat

207 (Despres and Lemieux, 2006).

209 In part because cortisol is readily measured in saliva and urine, as well as in

210 blood, there are numerous field studies of human cortisol. Many studies focus on short-

211 term cortisol dynamics in relation to psycho-social stress. Field studies of longer term

212 effects have focused on immune function, pregnancy, and lactation (Cohen et al., 2012;

213 Janicki-Deverts et al., 2016; Nepomnaschy et al., 2006; Oaks et al., 2016; Valeggia and

214 Ellison, 2004; Valeggia and Ellison, 2003).

215

216 b. Efficiency of ATP production

218 At the cellular level the utilization of oxidizable substrates is auto-regulated by the 219 accumulation of downstream products, and thus ultimately driven by energy 
220 expenditure. However, basal metabolic rate, the baseline turnover of energy substrates

221 in the body, is itself subject to hormonal regulation. Among the most potent regulators

222 of basal metabolism are the thyroid hormones, especially thyroxine (T4). Under

223 conditions of chronic energetic stress, such as fasting and starvation, T4 is lowered,

224 resulting in a lower baseline rate of energy consumption by the body (McAninch and

225 Bianco, 2014).

226

227 Up-regulation of T4 production can be part of an adaptive response to cold stress

228 (Leonard et al., 2005; Leppaluoto et al., 2005). The efficiency of ATP production by the

229 mitochondrial electron transport chain in some tissues, particularly brown fat, is

230 regulated by $\mathrm{T} 4$ through the up-regulation of uncoupling protein (UCP) (Busiello et al.,

2312015 ; Leppaluoto et al., 2005). UCP decouples the return flow of hydrogen ions across

232 the mitochondrial inner membrane from ATP production, resulting in an increased

233 production of heat. UCP is particularly abundant in brown adipose tissue which can

234 assist in the regulation of core body temperature, particularly in infants. Field studies of

235 high latitude populations have also demonstrated seasonal shifts in T4 production and

236 basal metabolism in adults associated with recurrent cold stress, a response that

237 appears to be greater in populations native to high latitudes than to more recent

238 migrants (Leonard et al., 2014; Levy et al., 2013; Tkachev et al., 1991).

241 Insulin-independent maintenance effort 
243 Energy allocation is organized hierarchically. Wade and Jones (Wade and

244 Jones, 2004) schematically represent this hierarchy in three levels: functions that must

245 be maintained at or near normal levels at all times; functions that can be down-

246 regulated at need, but cannot easily be interrupted for long periods; and functions that

247 can be interrupted at need for extended periods. The top priority functions include the

248 maintenance of brain function via the constant maintenance of membrane

249 depolarization as well as indispensable vegetal activities such as heart and respiratory

250 function, and some aspects of kidney and liver function. Mid-level priority functions

251 include physical activity, immune function, and protein anabolism. Dispensable or

252 interruptible functions include growth and reproduction, although these are also subject

253 to mid-level down-regulation as well as interruption.

255 Reproductive state can reorganize this hierarchy somewhat in females. During

256 pregnancy and lactation fetal growth and infant nutrition assume relatively high

257 priorities, at or near the top level. The interruption of female fecundity by pregnancy

258 and early lactation can be viewed as evidence of the priority of the fetus and infant over

259 lower level maternal priorities. The down-regulation of maternal basal metabolism that

260 can occur during pregnancy and lactation when energy availability is limited, noted

261 above, can be seen as evidence of the higher metabolic priority assigned to the fetus

262 and infant than mid-level priorities of the mother. 
Top-level metabolic priorities are largely insulin-independent (Fernandez-Real

265 and Ricart, 2003). The brain and fetus are particularly clear examples of insulin-

266 independent substrate uptake. Energy flow to these priorities is regulated only by the

267 availability of oxidizable substrates in the blood. The role of cortisol, glucagon, and

268 epinephrine can be best understood as buffering energy flow to top-level functions.

269 That is, when energy demands increase at lower levels, such as those precipitated by

270 "fight or flight" scenarios, these hormones increase the levels of oxidizable substrates in

271 the blood so that the new demands can be met without compromising top-level

272 functions. Down-regulation of competing demands for oxidizable substrates can also

273 increase their availability for top level functions. Physiological responses to fasting and

274 starvation, for example, include down-regulation of mid-level and low-level functions to

275 free up energy for the top priority functions (Keys et al., 1950).

276

\section{Energy allocation to storage and anabolic effort}

279 In textbooks the role of insulin at the organismic level is most often presented in

280 terms of glucose homeostasis, its function being to stimulate the clearance of excess

281 circulating glucose (Widmaier et al., 2013). But this is a poor and incomplete

282 characterization of its function. Insulin does not simply facilitate removal of glucose

283 from the blood, a function also performed by the kidney. It stimulates the uptake of

284 glucose by target tissues especially for storage in adipose tissue and to support protein

285 anabolism. Insulin also stimulates mitotic activity in many target tissues which, in 
286 conjunction with its anabolic effects, can promote cellular proliferation and tissue growth 287 (Sandow, 2009).

Viewed in these terms, the key role of insulin is to promote energy allocation to

290 medium and low priority metabolic functions on a facultative basis, not simply the

291 regulation of circulating glucose levels. When metabolic energy is available in excess of

292 high and mid-level category requirements, insulin promotes the diversion of the excess

293 either to storage or to anabolism. Similarly, the "counter-regulatory hormones" cortisol,

294 glucagon, and epinephrine, do not simply counter-balance the effects of insulin on blood

295 glucose, but buffer the flow of energy to top-level metabolic functions from fluctuations

296 in intake and lower level demands independently of insulin. The balance of these

297 hormones results in the hierarchical regulation of energy flow within the body, not simply

298 in the avoidance of the pathological consequences of hyperglycemia.

Insulin was one of the first protein hormones to be isolated, characterized, and

301 used therapeutically, due to its clinical importance in the pathogenesis and treatment of

302 diabetes mellitus (Sanger and Tuppy, 1951a, b). In this context, a great deal is known

303 about short-term insulin dynamics in relation to changes in blood glucose. But recently

304 a new approach, based on measurement of C-peptide of insulin in urine, has been

305 utilized to study longer-term changes in baseline insulin levels under field conditions

306 and not in the context of disease (Sherry and Ellison, 2007). C-peptide of insulin is a

307 section of the pro-insulin molecule that is cleaved in the production of active insulin. It is 
308 produced in a 1:1 ratio to active insulin and is cleared intact into the urine. Thus

309 measurement of urinary C-peptide, indexed by time, creatinine, or specific gravity, can

310 be used as a proxy measurement of insulin production. Urinary C-peptide measured in

311 samples collected in the field has been used to study longitudinal and cross-sectional

312 variation in energy balance in Samoa (Sherry and Ellison, 2007; Sherry et al., 2014),

313 Argentina (Ellison and Valeggia, 2003; Valeggia and Ellison, 2001, 2004; Valeggia and

314 Ellison, 2003), and The Gambia (Reiches et al., 2013; Reiches et al., 2014), among

315 other settings.

\section{Biasing of energy allocation towards growth effort}

Insulin controls energy allocation to lower priority metabolic categories, including

321 energy storage, and the anabolic categories growth and reproduction. The triage of

322 energy allocation among these competing categories, however, is largely under the

323 control of a trio of phylogenetically related protein hormones: growth hormone $(\mathrm{GH})$,

324 prolactin $(\mathrm{PRL})$, and human placental lactogen $(\mathrm{hPL})$. The genes for growth hormone

325 and human placental lactogen are both located on chromosome 17 and display $\sim 96 \%$

326 sequence homology, indicating common ancestry through a gene duplication event.

327 PRL is more distantly related, located on chromosome 6 and displaying $\sim 85 \%$

328 sequence homology with $\mathrm{GH}$. GH and PRL are both synthesized and secreted by

329 acidophilic cells of the anterior pituitary, while the hPL gene is expressed in the 
330 placenta. All three hormones have suppressive effects on whole body insulin

331 sensitivity, primarily through an inhibition of glucose uptake by somatic adipose tissue.

332 At the same time, however, all three synergize with insulin in promoting anabolic

333 processes in target tissues: accumulation of skeletal and lean body mass in the case of

$334 \mathrm{GH}$, mammary gland glucose uptake and milk synthesis in the case of PRL, and fetal

335 glucose transfer and fetal growth in the case of hPL (Forsyth and Wallis, 2002; Goffin et

336 al., 1996; Wallis et al., 2005).

The secretion of these hormones varies with maturational and reproductive

339 status, resulting in the differential allocation of available metabolic energy among these

340 anabolic categories. GH follows a steep decline following birth as the high rate of infant

341 growth declines to low levels in mid-childhood, but it undergoes an endogenous rise in

342 puberty, serving to promote skeletal and lean body growth (Bona et al., 1999; Rose et

343 al., 1991). At the same time, by increasing insulin resistance in adipose tissue it limits

344 energy allocation to storage and causes a transient rise in basal insulin levels (Guercio

345 et al., 2002). hPL by the placenta increases through pregnancy, elevating insulin

346 resistance in the mother and increasing the flow of metabolic energy to the fetus

347 (Braunstein, 2003; Mesiano and Jaffe, 2004). PRL production during lactation is

348 stimulated by infant nursing demand and acts to promote the uptake of glucose and

349 fatty acids by the mammary gland and the production of milk. At the same time it

350 increases insulin resistance in maternal adipose tissue, resulting in a diversion of

351 metabolic energy to milk production (Molitch, 2004). 
353 There is a long history of measuring prolactin in field studies of lactation (see

354 (Ellison, 1995) and growth hormone in studies of human growth (see Bogin, 1999).

355 Studies of hPL are confined to clinical settings.

358 Energy allocation to reproductive effort

360 Energy allocation to reproductive effort is primarily reflected and governed by

361 gonadal steroids (Ellison, 2003b). In females, ovarian steroids directly modulate

362 fecundity, influence sexual attractiveness to males as well as receptive and proceptive

363 sexual behavior, and promote energy storage in adipose tissue (an important form of

364 somatic reproductive effort in females). In males, testosterone maintains sperm

365 production, stimulates libido and mating effort and may also support increased social

366 confidence and assertiveness, and promotes increases in muscle mass (an important

367 form of somatic reproductive effort in males).

The production and release of gonadal steroids is governed by the gonadotropin

370 hormones, follicle stimulating hormone (FSH) and luteinizing hormone (LH) secreted by

371 the anterior pituitary. However, the effectiveness of this gonadotropin stimulation

372 depends strongly on insulin, so strongly that insulin is sometimes characterized as a co-

373 gonadotropin (Poretsky et al., 1999; Poretsky and Kalin, 1987). This effect has been 
374 mostly clearly demonstrated in in vitro studies of steroid production by cultured ovarian

375 granulose cells, where insulin receptor has been identified as the mediator of the effect,

376 increasing the rate of steroid production per cell.

378 Gonadal steroids, in their turn, synergize with insulin in promoting somatic

379 reproductive effort in both sexes, promoting increases in muscle mass in males

380 (androgens) and increases in adipose mass in females (estrogens) (Grumbach and

381 Styne, 2003). The mutual synergies between insulin and gonadal steroids constitute a

382 positive feedback loop that can dramatically up-regulate the flow of metabolic energy to

383 reproductive effort to take advantage of conditions of positive energy balance and the

384 availability of metabolic energy in excess of the needs of high priority categories.

The advent of practical methods for assaying gonadal steroids in saliva (Ellison,

387 1988; Lipson and Ellison, 1989), in addition to blood and urine, led to a rapid increase in

388 the number of field studies of gonadal steroids in human populations. Many examples

389 are provided elsewhere in this issue.

391 Hormonal gating of energy allocation

The hormonal framework described above governs the allocation of available

394 metabolic energy to competing domains in a hierarchical way. Top priority metabolic

395 categories, including brain and vegetal physiology, as well as fetal growth and infant 
396 nutrition during pregnancy and lactation, receive energy in direct proportion to its

397 availability. That availability is determined by the hormones that mobilize oxidizable

398 substrates and those that govern the rate and efficiency of ATP production as well as by

399 the competing demands of physical activity.

400

401 Insulin controls the gate for allocation of energy to lower level, "dispensable"

402 categories such as energy storage, growth, and reproduction. Cortisol opposes this

403 allocation, increasing the availability of metabolic energy to mid-level categories such as

404 immune function as well as buffering top level allocations. Allocation of metabolic

405 energy among potentially competing lower level categories is governed by $\mathrm{GH}, \mathrm{PRL}$,

$406 \mathrm{hPL}$, and gonadal steroids interacting with and modifying the action of insulin.

408 The dynamic interaction of the key hormones governing energy allocation helps

409 to organize key life history transitions. Puberty and postpartum resumption of ovarian

410 function are two particularly clear examples and will be considered here in some detail.

\section{The pubertal transition}

$414 \quad$ Puberty involves a transition in energy allocation from growth to adult

415 reproductive potential during which the body is modified, sexual dimorphism is

416 elaborated, and reproductive potential is established (Ellison et al., 2012). Although not

417 as dramatic as the metamorphosis of holometabolous insects or most amphibians, it is 
418 the human equivalent, changing juvenile morphology to a distinctively adult pattern and

419 elaborating immature, nonfunctional reproductive organs into mature, functioning ones.

420 Puberty involves the close coordination of primary reproductive maturation with the

421 rapid growth and transformation of the body. Reproductive maturation involves the

422 appearance (or, more properly, reappearance) of pulsatile release of gonadotropin

423 releasing-hormone $(\mathrm{GnRH})$ by the median eminence of the hypothalamus, which in turn

424 stimulates increased production of FSH and LH (Grumbach and Styne, 2003). The

425 factors that determine this change in $\mathrm{GnRH}$ production are still incompletely understood,

426 but the change begins quite early, well before internal or external manifestations of

427 increasing gonadal activity. The skeletal growth spurt that is typical of puberty is

428 primarily caused by an endogenous increase in $\mathrm{GH}$ and its downstream consequences

429 (Grumbach and Styne, 2003). Again, the causes of the increase in GH secretion are

430 incompletely understood, but its timing is roughly synchronous with the first appearance

431 of pulsatile gonadotropin secretion, suggesting a linkage between the two events (Suter,

432 2004; Gahete et al., 2016). The elaboration of somatic sexual dimorphism results from

433 the interaction of pubertal growth with rising titers of gonadal steroids. Differential

434 growth between the sexes resulting in adult sexual dimorphism is mediated by gonadal

435 steroids, both androgens and estrogens (Ellison et al., 2012).

437 The hormonal management of energy allocation during the pubertal transition

438 can be sketched out in terms of the framework described above. We assume that the

439 process is set in train when pulsatile $\mathrm{GnRH}$ reappears and $\mathrm{GH}$ begins to rise, even if the 
440 direct causes of those two events remain to be fully understood. Rising levels of $\mathrm{GH}$

441 stimulate growth and divert energy away from storage. The elevated $\mathrm{GH}$ also results in

442 increasing insulin resistance in adipose tissue, causing basal levels of insulin to rise.

443 Rising insulin would synergize with the increasing gonadotropin titers resulting from

444 increasingly stable GnRH pulses to promote gonadal steroid production and release.

445 As they approach mature levels, gonadal steroids in turn will potentiate the peripheral

446 effects of insulin, leading to a shift back toward lower insulin levels and increased

447 energy allocation to fat storage (in females) and muscle mass (in males), now as

448 sexually dimorphic forms of somatic reproductive effort. Even as they shift the direction

449 of energy allocation, gonadal steroids cause the closure of epiphyseal growth plates

450 and the cessation of skeletal growth as well as causing the remodeling of the female 451 pelvis.

452

$453 \quad$ In this way the pubertal transition unfolds as an endogenous process governed

454 by the interaction of the endocrine framework of energy allocation and its integration

455 with the growth and maturational processes involved. Energy allocation is first diverted

456 away from storage to support somatic growth and transformation and then returned to

457 storage as well as sexually dimorphic somatic forms of reproductive effort. A

458 characteristic and transient period of hyperinsulinemia is a central part of the process,

459 helping to accelerate gonadal steroid production to its mature levels. The mature

460 steroid levels in turn resolve the transient insulin resistance. 
This schema is consistent with observations of shifting energy allocation priorities

463 in female Gambian adolescents (Reiches et al., 2014). In the midst of the pubertal

464 transition, when skeletal growth is still underway, Gambian girls will respond to periods

465 of energetic stress by defending lean body mass at the expense of fat mass, but later in

466 the process as skeletal growth comes to a halt the same periods of energetic stress are

467 associated with a defense of fat mass at the expense of lean body mass. The

468 metabolic priority given to growth early gives way to a metabolic priority of somatic

469 reproductive effort late (Figure 3).

470

471 A mathematical model of the pubertal transition

472

The smooth, autonomous nature of the transition can also be demonstrated in a

474 quantitative model of female puberty. The specifics of the model are provided in

475 Supplementary Materials. The point of the model is to demonstrate that the interactions

476 between the principal hormonal regulators reviewed above act like interlocking gears,

477 so that changes in one component drive changes in the system as a whole. The shape

478 of the changes that ensue is a function of the feedback links within the system. The

479 central set of interactions are those between insulin directing energy to anabolic effort,

480 the pituitary proteins (prolactin, growth hormone, placental lactogen) biasing energy to

481 growth effort and feeding back on insulin through their effects on somatic insulin

482 resistance, and the gonadal steroids (estradiol, progesterone, and testosterone) biasing

483 energy to reproductive effort and feeding back negatively on the pituitary proteins 
484 regulating growth effort. Because the interactions of these hormones are interlocking,

485 the system as a whole can be changed by changes in any one of the components. But

486 the nature of the interactions causes the system to "switch" from a bias toward growth

487 effort to a bias toward reproductive effort, a switch that reflects the essential nature of a

488 life history transition as defined in this paper. Both the transition from growth to

489 reproduction at puberty (described here) and the resumption of ovarian function

490 postpartum (described below) can be modeled by the same system of interactions.

491

492

The assumptions and parameter settings of the quantitative models are meant to 493 be as simple as possible. In the model of the pubertal transition, $\mathrm{GH}$ is assumed to be

494 the independent driving factor, with all other variables dependent on it. In fact, the 495 initiation of the GH rise remains something of a mystery. There is mounting evidence 496 suggesting that the rise in GH may be tied to the same neural mechanisms, including 497 kisspeptin signaling to the pituitary, that disinhibit $\mathrm{GnRH}$ pulsatility in the hypothalamus 498 (Gahete et al., 2016). This would suggest that the initiation of the $\mathrm{GH}$ rise and the 499 nocturnal, sleep-associated appearance of pulsatile LH may be more or less coincident 500 (Apter, 1997, Suter 2004). In any event, increases in GH ordinarily precede detectable 501 increases in gonadal steroids (Rogol, 2010). So in this model the assumption is made 502 that a rise in $\mathrm{GH}$ starts the transition.

$504 \quad$ GH is assumed to fall steeply with age prior to puberty in parallel with growth 505 velocity (Bona et al., 1999; Rose et al., 1991; Chemaitilly et al., 2003), according to a 
506 rational function (a simple mathematical expression for a pattern of smooth, asymptotic

507 decline (Otto and Day, 2007), with an endogenous, normally shaped rise and fall

508 beginning at about age 8 years and centered on age 12.5 years. These ages are

509 arbitrary, but are chosen to reflect contemporary observations of adolescent growth for

510 females in the US and other developed nations where high quality longitudinal data are

511 available (Kuczmarski et al., 2002). For males, the age parameters can be set

512 approximately two years later. The normal shape of the GH rise during puberty is an

513 arbitrary assumption that generally reflects the observed pattern (Albertsson-Wikland et

514 al., 1994). The exact shape of the trajectory isn't important to the model; what is

515 important is that GH undergoes a rise at puberty before falling to adult levels.

517 Insulin, independent of the effect of $\mathrm{GH}$, is assumed to follow a slow logistic rise

518 from childhood to adult levels (Ballerini et al., 2016). However, the effect of GH on

519 insulin resistance, assumed to be proportional to the level of $\mathrm{GH}$, results in a transient

520 increase in insulin. Estradiol, in the absence of insulin, is assumed to follow a slow

521 logistic rise to adult levels, becoming noticeable (about $10 \%$ of adult levels) at about the

522 same time as the start of the GH rise, driven by gonadotropin levels that are themselves

523 responding to the resumption of pulsatile $\mathrm{GnRH}$ release. The logistic form of the

524 estradiol trajectory is arbitrary but is a simple mathematical form that can be used to

525 model sigmoid patterns (Otto and Day, 2007). A dummy factor ("lag") is introduced to

526 center the inflection point of the estradiol at about 12.5 years (around the time of

527 menarche) and an asymptotic approach to adult levels at around 20 years. This pattern 
528 reflects empirical observations indicating continued increases in ovarian function for a

529 number of years after menarche until at least the late teens/early twenties (Lipson and

530 Ellison 1992, Ellison 1996). Under the stimulating influence of insulin, assumed to be

531 proportional to insulin level, the rise in estradiol becomes steeper and overshoots final

532 adult levels slightly before converging on them in the late teens. Growth rate is

533 assumed to be proportional to GH levels, minus a braking effect assumed to be

534 proportional to estradiol levels, resulting from the action of estradiol in accelerating the

535 closure of the epiphyses of the long bones. The breaking effect of estradiol results in a

536 more rapid deceleration of growth that reaches its steepest decline at about the time of

537 menarche. The resulting pattern is represented in Figure 4. As noted above, the

538 parameters have been arbitrarily set to reflect the timing of puberty similar to that in the

539 US and other industrialized populations. Delay in the initial rise in GH would shift the

540 entire pattern to the right, typical of later puberty. Substitution of testosterone for

541 estradiol, together with a later onset of the GH rise, would generate a model typical of

542 males. Note that testosterone conversion to estradiol in the growth plates results in the

543 same breaking effect on linear growth as in females. Note also that the model does not

544 specify exact hormone levels, but only relative levels, with 1.0 representing typical adult 545 values.

547 The postpartum resumption of ovarian function 
A second example of the hormonal orchestration of a life history transition is the

550 postpartum resumption of ovarian function. In this case, a transition occurs between

551 energetic allocation to milk and energetic investment in fecund reproductive capacity.

552 The transition unfolds in a manner very reminiscent of the pubertal transition, with PRL

553 taking on the role played by GH during puberty. In a lactating mother early in the

554 postpartum period milk production assumes a high priority. It is driven by PRL secretion

555 which is responsive to infant demand but also reflective of maternal energy availability

556 (Ellison, 1995). When infants are exclusively breastfed by mothers facing energetic

557 constraints, PRL levels will be high and insulin levels low. PRL directs energy toward

558 milk production by increasing the insulin resistance of peripheral maternal adipose

559 tissue (though there is also evidence that PRL increases insulin sensitivity in mammary

560 adipose tissue). Gonadal activity is extremely low, though FSH levels are near normal

561 (McNeilly et al., 1994), suggesting ovarian resistance to gonadotropin stimulation.

563 Later in the postpartum period PRL levels begin to decline. This occurs most

564 often as a consequence of the introduction of supplementary foods into the infant's diet

565 (McNeilly et al., 1994), reducing the demand for milk. Reduced energy demand for milk

566 production results in increased energy availability to the mother and rising levels of

567 basal insulin. Energy allocation to storage rises as a consequence, but PRL levels

568 remain sufficient to cause elevated insulin resistance. As a result, insulin levels rise

569 above the typical level for the mother, manifesting a brief, transient period of

570 hyperinsulinemia. This transient period of hyperinsulinemia, although briefer in 
571 duration, is very reminiscent of the transient period of elevated insulin in puberty. The

572 elevated insulin synergize with FSH levels to stimulate ovarian steroid production

573 toward normal mature levels. The rising titers of estradiol that result in turn potentiate

574 energy storage in adipose tissue, increasing adipose insulin sensitivity and returning

575 insulin levels to normal.

576

577 As with the pubertal transition, the resumption of postpartum ovarian function is

578 governed endogenously by the endocrine architecture of energy allocation. Insulin once

579 again plays a central role, modified by the actions of PRL and gonadal steroids. The

580 unfolding sequence is clearly displayed by Toba mothers in Argentina (Ellison and

581 Valeggia, 2003; Valeggia and Ellison, 2001, 2004; Valeggia and Ellison, 2003) (Figure

582 5), and a comparable pattern has even been observed in wild chimpanzees in Uganda

583 (Emery Thompson et al., 2012).

584

585 A mathematical model of the postpartum resumption of ovarian function

As with the pubertal transition, the smooth, endogenous nature of the resumption

588 of ovarian function postpartum can be represented in a qualitative model (details in

589 Supplementary Materials). This model includes analogous hormonal interactions to

590 those presented in the puberty model above. In this case, PRL level is assumed to be

591 the independent driving factor with other variables being dependent on it. Prolactin is

592 assumed to decline following a logistic function (a simple expression for a sigmoid 
593 pattern, Otto and Day, 2007) and to represent the energy demand for milk production.

594 In the version of the model presented here the decline in PRL is parameterized to return

595 to baseline by 40 months with a maximal rate of decline at $18-20$ months. This is an

596 arbitrary parameterization designed to reflect patterns observed in the Toba (Valeggia

597 and Ellison, 2004). Different values for the parameters of the logistic could be chosen

598 to reflect earlier or later weaning or other factors affecting energy availability. Energy

599 availability for lower level priorities than milk production is assumed to be proportional to

600 the complement of PRL (where peak PRL is set at 1.0 as a reference). Insulin is

601 expected to be proportional to energy availability, but modified by the insulin resistance

602 caused by prolactin. If insulin sensitivity were constant, insulin levels would rise

603 proportionally to energy availability. However, due to the declining effect of prolactin on

604 insulin resistance, insulin rises more steeply and overshoots typical "post lactation"

605 levels (set at 1.0). Estradiol levels rise proportionally to insulin with a slight, arbitrary lag

606 time, while postpartum weight gain is proportional to the product of energy availability

607 and insulin. The resulting pattern is represented in Figure 6 with parameters adjusted to

608 be roughly equivalent to observations made on the Toba. Once again, variable values

609 are relative with 1.0 representing adult, non-lactating values of all variables except PRL,

610 where 1.0 represents peak values early in lactation.

611

612 The heuristic value of the mathematical model is to make explicit the fact that the

613 mutual interactions of a core set of hormones regulating energy allocation, interactions

614 that are well-established in the literature, are sufficient to generate the rather complex 
615 trajectories of hormones and anabolic variables (e.g., growth rate, milk production,

616 weight gain) that are observed during two important life history transitions, puberty and

617 the post-partum resumption of ovarian function. It is not necessary to assume any

618 special set of interactions or drivers to generate these patterns. Rather the "switch"

619 from growth effort to reproductive effort is latently embedded in the effect these

620 important regulators have on each other. Natural selection has been able to leverage

621 the same endocrine architecture to orchestrate two different life history transitions by

622 making use of two different, but phylogenetically related, modifiers of anabolic energy

623 allocation, GH and PRL. Although beyond the scope of this paper, it can be argued that

624 this architecture has analogues in other vertebrates (Chandrashekar and Bartke, 2003,

625 Kawashima et al., 2007, Flatt and Heyland, 2011).

\section{Concluding comments}

The model framework presented here is just that: a model that represents only a

631 few of the major features of a complex network or interacting signals that govern human

632 energetic allocation. Its heuristic value is illustrated in its ability to capture the major

633 signals and interactions in sufficient detail to illuminate the dynamic aspects of the

634 control of energy allocation during major life history transitions. In doing so, it helps to

635 connect our knowledge of the mechanisms that govern energy allocation with the

636 predictions and tradeoffs that feature in life history theory. As a major branch of 
637 evolutionary theory, life history theory has proven very powerful in predicting and

638 explaining major features of life history diversity, and in doing so it leans very heavily on

639 generalized concepts of energetic tradeoffs. But less effort has been made to integrate

640 life history theory with proximate mechanisms until recently (Flatt and Heyland, 2011).

The model presented here also underscores the central role of insulin, not as a

643 gluco-regulatory hormone, but as the major gatekeeper of energy allocation to mid- and

644 lower level physiological priorities. Insulin does not simple clear glucose from the

645 circulation to guard against negative effects of hyperglycemia, it directs energy toward

646 growth and reproductive effort, synchronizing investment in those physiological

647 categories with the availability of metabolic energy over and above the requirements of

648 higher priority categories. This centrality of insulin in the modulation of energy

649 allocation helps to make sense of the phylogenetically highly conserved relationship

650 between insulin and insulin-like signaling and lifespan variation (Barbieri et al., 2003;

651 Singleton, 2011; Tatar et al., 2003). Insulin is one of the best known and longest

652 studied human hormones. It may not have the cachet of more recently identified

653 neuropeptides and cytokines, nor does it represent control of the soma by the CNS. Yet

654 its role in life history energetics is crucial.

655

656 Finally, although developed in the context of human physiology, there is reason

657 to suspect that the framework presented here may have more general application,

658 either directly or as a template to modify and build on. The comparability of the 
659 trajectory of C-peptide of insulin in relation to the postpartum resumption of ovarian

660 function in humans and chimpanzees is one example that supports this notion. The

661 framework developed and presented here may serve as an impetus for comparative

662 studies of the hormonal architecture of energy allocation in non-human primates and

663 mammals generally.

664 
667 Albertsson-Wikland, K., Rosberg, S., Karlberg, J., Groth, T., 1994. Analysis of 24-hour 668 growth hormone profiles in healthy boys and girls of normal stature: relation to puberty.

669 J Clin Endocrinol Metab 78(5): 1195-1201.

670 Apter, D., 1997. Development of the hypothalamic-pituitary-ovarian axis. Ann N Y

671 Acad Sci 816:9-21.

672 Badman, M.K., Flier, J.S., 2005. The gut and energy balance: visceral allies in the 673 obesity wars. Science 307, 1909-1914.

674 Ballerini, M.G., Bergadá, I., Rodríguez, M.E., Keselman, A., Bengolea, V.S., Pipman, V.,

675 Domené, H.M., Jasper, H.G., Ropelato, M.G., 2016. Arch Argent Pediatr 114(4):328676336.

677 Barbieri, M., Bonafe, M., Franceschi, C., Paolisso, G., 2003. Insulin/IGF-I-signaling 678 pathway: an evolutionarily conserved mechanism of longevity from yeast to humans.

679 Am J Physiol Endocrinol Metab 285, E1064-1071.

680 Blundell, J.E., Finlayson, G., Gibbons, C., Caudwell, P., Hopkins, M., 2015a. The 681 biology of appetite control: Do resting metabolic rate and fat-free mass drive energy 682 intake? Physiol Behav 152, 473-478.

683 Blundell, J.E., Gibbons, C., Caudwell, P., Finlayson, G., Hopkins, M., 2015b. Appetite 684 control and energy balance: impact of exercise. Obes Rev 16 Suppl 1, 67-76.

685 Bogin, B.A., 1999. Patterns of Human Growth, 2nd Ed., 2 ed. Cambridge University 686 Press, Cambridge, UK. 
687 Bona, G., Petri, A., Conti, A., Sartorio, A., 1999. The impact of gender, puberty and 688 body mass on reference values for urinary growth hormone $(\mathrm{GH})$ excretion in normally 689 growing non-obese and obese children. Clinical Endocrinology 50, 775-781.

690 Braunstein, G.D., 2003. Endocrine changes in pregnancy, in: Larsen, P.R., Kronenberg, 691 H.M., Melmed, S., Polonsky, K.S. (Eds.), Williams textbook of endocrinology, 10th Ed., 69210 ed. Saunders, Philadelphia, PA, pp. 795-810.

693 Bribiescas, R.G., 2001. Serum leptin levels and anthropometric correlates in Ache 694 Amerindians of eastern Paraguay. Am J Phys Anthropol 115, 297-303.

695 Bribiescas, R.G., 2005. Serum leptin levels in Ache Amerindian females with normal 696 adiposity are not significantly different from American anorexia nervosa patients.

697 American journal of human biology : the official journal of the Human Biology Council $698 \quad 17,207-210$.

699 Bribiescas, R.G., Hickey, M.S., 2006. Population variation and differences in serum 700 leptin independent of adiposity: a comparison of Ache Amerindian men of Paraguay and 701 lean American male distance runners. Nutr Metab 3, 34-40.

702 Busiello, R.A., Savarese, S., Lombardi, A., 2015. Mitochondrial uncoupling proteins and 703 energy metabolism. Front Physiol 6, 36.

704 Chemaitilly, W., Trivin, C., Souberbielle, J. C., Brauner, R., 2003. Assessing short705 statured children for growth hormone deficiency. Horm Res 60(1):34-42.

706 Cohen, S., Janicki-Deverts, D., Doyle, W.J., Miller, G.E., Frank, E., Rabin, B.S., Turner, 707 R.B., 2012. Chronic stress, glucocorticoid receptor resistance, inflammation, and 
708 disease risk. Proceedings of the National Academy of Sciences of the United States of

709 America 109, 5995-5999.

710 Crespo, C.S., Cachero, A.P., Jiménez, L.P., Barrios, V., Ferreiro, E.A., 2014. Peptides

711 and food intake. Frontiers in Endocrinology 5.

712 Despres, J.P., Lemieux, I., 2006. Abdominal obesity and metabolic syndrome. Nature $713444,881-887$.

714 Ellison, P.T., 1988. Human salivary steroids: methodological considerations and

715 applications in physical anthropology. Yearbook of Physical Anthropology 31, 115-132.

716 Ellison, P.T., 1995. Breasfeeding, fertility, and maternal condition, in: Dettwyler, K.A.,

717 Stuart-Macadam, P. (Eds.), Breasfeeding: Biocultural perspectives. Aldine de Gruyter,

718 Hawthorne, NY, pp. 305-345.

719 Ellison, P.T., 1996. Developmental influences on adult ovarian function. Am J Hum

$720 \quad$ Biol 8:725-734.

721 Ellison, P.T., 2003a. Energetics and reproductive effort. American Journal of Human

722 Biology 15, 342-351.

723 Ellison, P.T., 2003b. Energetics and reproductive effort. American journal of human

724 biology : the official journal of the Human Biology Council 15, 342-351.

725 Ellison, P.T., 2009. Social relationships and reproductive ecology, in: Ellison, P.T., Gray,

726 P. (Eds.), Endocrinology of social relationships. Harvard University Press, Cambridge,

727 MA, pp. 54-73.

728 Ellison, P.T., Reiches, M.W., Shattuck-Faegre, H., Breakey, A., Konecna, M., Urlacher,

729 S., Wobber, V., 2012. Puberty as a life history transition. Ann Hum Biol 39, 352-360. 
730 Ellison, P.T., Valeggia, C.R., 2003. C-peptide levels and the duration of lactational

731 amenorrhea. Fertility and sterility 80, 1279-1280.

732 Emery Thompson, M., Muller, M.N., Wrangham, R.W., 2012. The energetics of lactation

733 and the return to fecundity in wild chimpanzees. Behavioral Ecology 23, 1234-1241.

734 Fernandez-Real, J.M., Ricart, W., 2003. Insulin resistance and chronic cardiovascular

735 inflammatory syndrome. Endocrine reviews 24, 278-301.

736 Flatt, T., Heyland, A., 2011. Mechanisms of life history evolution: The genetics and

737 physiology of life history traits and trade-offs. Oxford University Press, Oxford.

738 Forsyth, I.A., Wallis, M., 2002. Growth hormone and prolactin--molecular and functional

739 evolution. Journal of mammary gland biology and neoplasia 7, 291-312.

740 Gahete, M.D., Vázquez-Borrego, M.C., Martínez-Fuentes, A.J., Tena-Sempere, M.,

741 Castaño, J.P., Luque, R.M., 2016. Role of the Kiss1/Kiss1r system in the regulation of

742 pituitary cell function. Mol Cell Endocrinol epub ahead of print (doi:

$743 \quad 10.1016 /$ j.mce.2016.07.039).

745 Goffin, V., Shiverick, K.T., Kelly, P.A., Martial, J.A., 1996. Sequence-function

746 relationships within the expanding family of prolactin, growth hormone, placental

747 lactogen, and related proteins in mammals. Endocrine reviews 17, 385-410.

748 Grumbach, M.M., Styne, D.M., 2003. Puberty: ontogeny, neuroendocrinology,

749 physiology, and disorders, in: Larsen, P.R., Kronenberg, H.M., Melmed, S., Polonsky,

750 K.S. (Eds.), Williams textbook of endocrinology, 10th Ed., 10 ed. Saunders,

751 Philadelphia, pp. 1115-1286. 
752 Guercio, G., Rivarola, M.A., Chaler, E., Maceiras, M., Belgorosky, A., 2002.

753 Relationship between the GH/IGF-I axis, insulin sensitivity, and adrenal androgens in

754 normal prepubertal and pubertal boys. The Journal of clinical endocrinology and

755 metabolism 87, 1162-1169.

756 Janicki-Deverts, D., Cohen, S., Turner, R.B., Doyle, W.J., 2016. Basal salivary cortisol

757 secretion and susceptibility to upper respiratory infection. Brain Behav Immun. epub

758 ahead of print (http://dx.doi.org/10.1016/j.bbi.2016.01.013)

759 Kawashima, C., Fukihara, S., Maeda, M., Kaneko, E., Montoya C.A., Matsui, M.,

760 Shimizu, T., Matsunaga, N., Kida, K., Miyake, Y.-I., Schams, D., Miyamoto, A., 2007.

761 Reproduction 133:155-163.

762 Keys, A., Brozek, J., Henschel, A., Mickelsen, O., Taylor, H.L., 1950. The biology of

763 human starvatin, vols. I-II. University of Minnesota Press, Minneapolis, MN.

764 Kuczmarski RJ, Ogden CL, Guo SS, et al. 2000. CDC growth charts for the United

765 States: Methods and development. National Center for Health Statistics. Vital Health

766 Stat 11(246). 2002

767 Kuzawa, C.W., Quinn, E.A., Adair, L.S., 2007. Leptin in a lean population of Filipino

768 adolescents. Am J Phys Anthropol 132, 642-649.

769 Leonard, W.R., Levy, S.B., Tarskaia, L.A., Klimova, T.M., Fedorova, V.I., Baltakhinova,

770 M.E., Krivoshapkin, V.G., Snodgrass, J.J., 2014. Seasonal variation in basal metabolic

771 rates among the Yakut (Sakha) of Northeastern Siberia. American journal of human

772 biology : the official journal of the Human Biology Council 26, 437-445. 
773 Leonard, W.R., Snodgrass, J.J., Sorensen, M.V., 2005. Metabolic adaptation in

774 indigenous Siberian populations. Annual Review of Anthropology 34, 451-471.

775 Leppaluoto, J., Paakkonen, T., Korhonen, I., Hassi, J., 2005. Pituitary and autonomic

776 responses to cold exposures in man. Acta Physiol Scand 184, 255-264.

777 Levy, S.B., Leonard, W.R., Tarskaia, L.A., Klimova, T.M., Fedorova, V.I., Baltakhinova,

778 M.E., Krivoshapkin, V.G., Snodgrass, J.J., 2013. Seasonal and socioeconomic

779 influences on thyroid function among the Yakut (Sakha) of Eastern Siberia. American

780 journal of human biology : the official journal of the Human Biology Council 25, 814-820.

781 Lipson, S.F., Ellison, P.T., 1989. Development of protocols for the applicatin of salivary

782 steroid analyses to field conditions. American Journal of Human Biology 1, 249-255.

783 Lipson, S.F., Ellison, P.T., 1992. Normative study of age variation in salivary

784 progesterone profiles. Journal of Biosocial Science 24:233-244.

785 McAninch, E.A., Bianco, A.C., 2014. Thyroid hormone signaling in energy homeostasis

786 and energy metabolism. Annals of the New York Academy of Sciences 1311, 77-87.

787 McNeilly, A.S., Tay, C.C., Glasier, A., 1994. Physiological mechanisms undelying

788 lactational amenorrhea. Ann N Y Acad Sci 709:145-155.

789 Meier, U., Gressner, A.M., 2004. Endocrine regulation of energy metabolism: review of

790 pathobiochemical and clinical chemical aspects of leptin, ghrelin, adiponectin, and

791 resistin. Clin Chem 50, 1511-1525.

792 Mesiano, S., Jaffe, R.B., 2004. The endocrinology of human pregnancy an feto-

793 placental neuroendocrine development, in: Straus, J.F., III, Barbieri, R.L. (Eds.), Yen 
794 and Jaffe's Reproductive Endocrinology, 5th Ed., 5 ed. Elsevier Saunders, Philadelphia, 795 PA, pp. 327-367.

796 Miller, A.A., Sharrock, K.C., McDade, T.W., 2006. Measurement of leptin in dried blood 797 spot samples. American journal of human biology : the official journal of the Human 798 Biology Council 18, 857-860.

799 Molitch, M.E., 2004. Prolactin in human reproduction, in: Straus, J.F., III, Barbieri, R.L.

800 (Eds.), Yen and Jaffe's Reproductive Endocrinology, 5 ed. Elsevier Saunders,

801 Philadelphia, PA, pp. 93-124.

802 Munch-Andersen, T., DSorensen, K., Aachmann-Andersen, N.-J., Aksglaede, L., Juul, 803 A., Helge, J.W., 2013. Ethnic differences in leptin and adiponectin levels between 804 Greenlandic Inuit and Danish children. Int J Circumpolar Health 72, 21458.

805 Nepomnaschy, P.A., Welch, K.B., McConnell, D.S., Low, B.S., Strassmann, B.I., 806 England, B.G., 2006. Cortisol levels and very early pregnancy loss in humans.

807 Proceedings of the National Academy of Sciences of the United States of America 103, 808 3938-3942.

809 Oaks, B.M., Laugero, K.D., Stewart, C.P., Adu-Afarwuah, S., Lartey, A., Ashorn, P.,

810 Vosti, S.A., Dewey, K.G., 2016. Late-pregnancy salivary cortisol concentrations of

811 Ghanaian women participating in a randomized controlled trial of prenatal lipid-based

812 nutrient supplements. J Nutr.

813 Otto, S. P., Day, T, 2007. A Biologist's Guide to Mathematical Modeling in Ecology and 814 Evolution. Princeton University Press, Princeton, NJ. 
815 Pelleymounter, M.A., Cullen, M.J., Baker, M.B., Hecht, R., Winters, D., Boone, T.,

816 Collins, F., 1995. Effects of the obese gene product on body weight regulation in ob/ob

817 mice. Science 269, 540-543.

818 Pinkney, J., 2014. The role of ghrelin in metabolic regulation. Current opinion in clinical

819 nutrition and metabolic care 17, 497-502.

820 Poretsky, L., Cataldo, N.A., Rosenwaks, Z., Giudice, L.C., 1999. The insulin-related

821 ovarian regulatory system in health and disease. Endocrine reviews 20, 535-582.

822 Poretsky, L., Kalin, M.F., 1987. The gonadotropic function of insulin. Endocrine reviews $8238,132-141$.

824 Reiches, M.W., E., M.S., Prentice, A.M., Prentice, A., Sawo, Y., Ellison, P.T., 2013. The

825 adolescent transition under stress: body composition tradeoffs among adolescent

826 women in The Gambia. Evol Med Publ Health 2013, 75-85.

827 Reiches, M.W., Moore, S.E., Prentice, A.M., Ellison, P.T., 2014. Endocrine responses,

828 weight change, and energy sparing mechanisms during Ramadan among Gambian

829 adolescent women. American journal of human biology : the official journal of the

830 Human Biology Council 26, 395-400.

831 Rogol, A.D., 2010. Sex steroids, groeth hormone, leptin, and the pubertal growth spurt.

832 Endocr Dev 17:77-85.

833 Rose, S.R., Municchi, G., Barnes, K.M., Kamp, G.A., Uriarte, M.M., Ross, J.L.,

834 Cassorla, F., Cutler, G.B., Jr., 1991. Spontaneous growth hormone secretion increases

835 during puberty in normal girls and boys. The Journal of clinical endocrinology and

836 metabolism 73, 428-435. 
837 Sandow, J., 2009. Growth effects of insulin and insulin analogues. Archives of

838 physiology and biochemistry $115,72-85$.

839 Sanger, F., Tuppy, H., 1951a. The amino-acid sequence in the phenylalanyl chain of

840 insulin. 2. The investigation of peptides from enzymic hydrolysates. The Biochemical

841 journal $49,481-490$.

842 Sanger, F., Tuppy, H., 1951b. The amino-acid sequence in the phenylalanyl chain of

843 insulin. I. The identification of lower peptides from partial hydrolysates. The Biochemical

844 journal $49,463-481$.

845 Schwartz, G.J., 2000. The role of gastrointestinal vagal afferents in the control of food

846 intake: current prospects. Nutrition 16, 866-873.

847 Schwartz, M.W., Woods, S.C., Porte, D., Jr., Seeley, R.J., Baskin, D.G., 2000. Central

848 nervous system control of food intake. Nature 404, 661-671.

849 Sharrock, K.C., Kuzawa, C.W., Leonard, W.R., Tanner, S., Reyes-Garcia, V.E., Vadez,

850 V., Huanca, T., McDade, T.W., 2008. Developmental changes in the relationship

851 between leptin and adiposity among Tsimane children and adolescents. American

852 journal of human biology : the official journal of the Human Biology Council 20, 392-398.

853 Sherry, D.S., Ellison, P.T., 2007. Potential applications of urinary C-peptide of insulin for

854 comparative energetics research. Am J Phys Anthropol 133, 771-778.

855 Sherry, D.S., McGarvey, S.T., Sesepasara, M.L., Ellison, P.T., 2014. Ovarian function in

856 Samoan women shows stronger association with signals of energy metabolism than fat

857 reserves. American journal of human biology : the official journal of the Human Biology

858 Council 26, 95-98. 
859 Singleton, A.W., 2011. Evolution and the regulation of growth and body size, in: Flatt,

860 T., Heyland, A. (Eds.), Mechanisms of life history evolution: The genetics and

861 physiology of life history traits and tradeoffs. Oxford University Press, New York, pp. 43-

86255.

863 Suter, K.J., 2004. The ontogeny of pulsatile growth hormone secretion and its temporal

864 relationship to the onset of puberty in the agonadal male rhesus monkey (Macaca

865 mulatta). J Clin Endocrinol Metab 89(5):2275-2280.

866 Tanaka, M., Umezaki, M., Natsuhara, K., Yamauchi, T., Inaoka, T., Hongo, T., Nagano,

867 M., Watanabe, C., Ohtsuka, R., 2005. No difference in serum leptin concentrations

868 between urban-dwelling Austronesians and Non-Austronesians in Papua New Guinea.

869 American journal of human biology : the official journal of the Human Biology Council

$870 \quad 17,696-703$.

871 Tatar, M., Bartke, A., Antebi, A., 2003. The endocrine regulation of aging by insulin-like

872 signals. Science 299, 1346-1351.

873 Tkachev, A.V., Bojko, J.R., Ramenskaya, E.B., 1991. Endocrine status and plama lipids

874 in inhabitants of the norther European part of the USSR. Arctic Medical Research 50,

$875 \quad 148-151$.

876 Valeggia, C., Ellison, P.T., 2001. Lactation, energetics, and postpartum fecundity, in:

877 Ellison, P.T. (Ed.), Reproductive ecology and human evolution. Aldine de Gruyter, New

878 York, pp. 85-105.

879 Valeggia, C., Ellison, P.T., 2004. Lactational amenorrhoea in well-nourished Toba

880 women of Formosa, Argentina. J Biosoc Sci 36, 573-595. 
881 Valeggia, C.R., Ellison, P.T., 2003. Impact of breastfeeding on anthropometric changes

882 in peri-urban Toba women (Argentina). American journal of human biology : the official 883 journal of the Human Biology Council 15, 717-724.

884 Wade, G.N., Jones, J.E., 2004. Neuroendocrinology of nutritional infertility. Am J

885 Physiol Regul Integr Comp Physiol 287, R1277-1296.

886 Wallis, O.C., Mac-Kwashie, O., Makri, G., Wallis, M., 2005. Molecular evolution of

887 prolactin in primates. Journal of Molecular Evolution 60, 606-614.

888 Webber, E.S., Bonci, A., Krashes, M.J., 2015. The elegance of energy balance: Insight

889 from circuit-level manipulations. Synapse 69, 461-474.

890 Widmaier, E., Raff, H., Strang, K., 2013. Vander's Human Physiology, 13th Ed.

891 McGraw-Hill, New York.

892 Wolf, G., 1996. Leptin: the weight-reducing plasma protein encoded by the obese gene.

893 Nutr Rev 54, 91-93.

894

895 


\section{Figure Captions}

899 Figure 1: The basic framework of energy flow underlying human life history energetics.

900 Numbers associated with the arrows refer to the groups of hormonal regulators

901 specified in Figure 2. The parenthetical number associated with energy flow from

902 available metabolic energy to activity indicates potentially weak or indirect hormonal

903 regulation.

904

905

906 Figure 2: Categories of hormonal regulators associated with the pathways of energy

907 flow specified in Figure 1. Examples of major hormonal regulators in each category are 908 given and further elaborated upon in the text.

909

910

911 Figure 3: Body composition changes (means \pm SE) in adolescent females in The

912 Gambia during periods of relative energy abundance (harvest season) and energy

913 constraint (hungry season) subdivided by growth rate. Details provided in Reiches et al.

9142014.

915

916 
917 Figure 4: Trajectories of growth hormone, growth rate, estradiol, and insulin during

918 puberty generated by a simple model of the basic framework of human life history

919 energetics presented in this paper and illustrated in Figure 1. The Y-axis units are

920 expressed in proportion to adult values for each variable. Details of the model are

921 provided in Supplementary Materials.

922

923

924 Figure 5: Plots of first morning urinary C-peptide of insulin levels expressed as a

925 proportion of individual, post-resumption average levels for each individual during the

926 postpartum lactation period as observed among Toba women compared with the

927 trajectories of $(\mathrm{A}) \mathrm{BMI}$ and $(\mathrm{B})$ urinary estrone conjugates (urinary metabolite of

928 estradiol). Compare these trajectories with those generated by the model depicted in

929 Figure 5. Data from Ellison and Valeggia 2003, Valeggia and Ellison 2001, 2003, 2004.

930

931

932 Figure 6: Trajectories of insulin, estradiol, postpartum weight gain, energy availability,

933 and prolactin during the postpartum lactating period generated by a simple model of the

934 basic framework of human life history energetics presented in this paper and illustrated

935 in Figure 1. The Y-axis units are expressed in proportion to adult values for each

936 variable. Details of the model are provided in Supplementary Materials. 
939 